\title{
Cell Growth Inhibition Effect of DsiRNA Vectorised by Pectin-Coated Chitosan-Graphene Oxide Nanocomposites as Potential Therapy for Colon Cancer
}

\author{
Haliza Katas, Mohd Cairul Iqbal Mohd Amin, Nursyafiqah Moideen, \\ Li Ying Ng, and Puteri Annisa Adhwa Megat Baharudin \\ Centre for Drug Delivery Research, Faculty of Pharmacy, Universiti Kebangsaan Malaysia, Jalan Raja Muda Abdul Aziz, \\ 50300 Kuala Lumpur, Malaysia
}

Correspondence should be addressed to Haliza Katas; haliz12@hotmail.com

Received 31 January 2017; Revised 5 April 2017; Accepted 19 April 2017; Published 25 May 2017

Academic Editor: Yan Zou

Copyright (C) 2017 Haliza Katas et al. This is an open access article distributed under the Creative Commons Attribution License, which permits unrestricted use, distribution, and reproduction in any medium, provided the original work is properly cited.

Colonic-targeted drug delivery system is widely explored to combat colon-related diseases such as colon cancer. Dicer-substrate small interfering RNA (DsiRNA) has been explored for cancer therapy due to its potency in targeting specific gene of interest. However, its application is limited by rapid degradation and poor cellular uptake. To address this, chitosan-graphene oxide (CSGO) nanocomposite was used to deliver DsiRNA effectively into cells. Additionally, pectin was used as compatibilization agent to allow specific delivery to the colon and protect the nanocomposites from the harsh environment in the stomach and small intestine. CS-GO-DsiRNA nanocomposites were prepared by electrostatic interaction between CS and GO prior to coating with pectin. The mean particle size of CS-GO-DsiRNA-pectin nanocomposites was $554.5 \pm 124.6 \mathrm{~nm}$ with PDI and zeta potential of $0.47 \pm 0.19$ and $-10.7 \pm 3.0 \mathrm{mV}$, respectively. TEM analysis revealed smooth and spherical shape of CS-GO-DsiRNA nanocomposites and the shape became irregular after pectin coating. FTIR analysis further confirmed the successful formation of CS-GO-DsiRNApectin nanocomposites. Furthermore, the nanocomposites were able to entrap high amount of DsiRNA (\% entrapment efficiency of $92.6 \pm 3.9 \%$ ) with strong binding efficiency. CS-GO-DsiRNA-pectin nanocomposites also selectively inhibited cell growth of colon cancer cell line (Caco-2 cells) and were able to decrease VEGF level significantly. In a nutshell, pectin-coated DsiRNA-loaded CS-GO nanocomposites were successfully developed and they have a great potential to deliver DsiRNA to the colon effectively.

\section{Introduction}

Colorectal cancer is ranked as the third most common cancer worldwide and it contributes to major cause of death in Western country [1]. Conventional treatments of colon cancer such as chemotherapy and radiotherapy have considerable drawbacks as they could not specifically target cancer cells and might cause injury to healthy cells [2]. Besides, patients on conventional treatment often develop tolerance to targeted therapy by gene mutation. Gene therapy has gained enormous interests recently as it can be used to treat wide range of diseases. An effective treatment approach by producing siRNA-based drug may target specific mRNAs despite of their cellular locations or structures of translated protein [3]. Kulisch et al. [4] reported that Dicer-substrate
siRNA (DsiRNA) displays excellent potency in gene silencing and is able to silence gene for longer time compared to siRNA. DsiRNA has several advantages compared to standard 21-mer siRNAs. The advantages include better selectivity of the guide strand as a consequence of Dicer processing and handoff to RNA-induced silencing complex (RISC) as well as higher potency attributed to lower effective concentration needed [5].

RNAi technology was reported to provide an alternative strategy in treating cancer by inhibiting overexpressed oncogenes, blocking cell division by interfering with related genes, or promoting apoptosis by suppressing antiapoptotic genes [6]. Vascular endothelial growth factor (VEGF) is an important angiogenic factor associated with tumor growth and metastasis [7]. According to Ahluwalia et al. [8], normal 
colonic epithelial cells do not produce VEGF or express its receptors. However, in colon cancer cells, VEGF and its receptors are expressed and it promotes colon cancer cell proliferation directly. Therefore, DsiRNA targeted against VEGF gene was used to kill cancer cells by silencing overexpression of its protein [6].

In a strategy to activate RNAi pathway, siRNA molecules need to be delivered to the interior of target cells and to be incorporated into the RNAi machinery. However, siRNAs cannot cross the lipid bilayers of the cell membrane readily as they have anionic backbone and hydrophilic properties [9]. Besides, siRNAs are facing some other obstacles to reach their site of action. The obstacles include undergoing degradation by nucleases, short half-life due to the uptake by mononuclear phagocyte system, off-target effect, and rapid renal clearance [10]. As a result of these obstacles, the need to develop carriers for siRNA is paramount to deliver it to the site of interest efficiently. An ideal delivery carrier for siRNA should possess properties such as being nontoxic and nonimmunogenic, being able to condense siRNA efficiently, protecting the integrity of its content before reaching the target site, having the ability to evade rapid elimination from blood circulation, and internalizing and dissociating in intracellular compartments of the target cells to release the adequate amount of siRNA, thereby exposing siRNA to mRNA [11].

Nanomedicine-based carriers have been extensively explored as potential candidates to guide siRNAs directly to the target cells. Nanocarriers offer several advantages that include providing sustained release and prolonging the time of siRNA at the target site. Nanocarriers also are able to penetrate capillaries; hence, they can accumulate at the site of interest. The nanotechnology approach could also protect siRNA against RNase degradation and avoid offtarget effects [12]. In nanomedicine, polycationic polymers such as chitosan (CS) were used to condense siRNA into nanoparticles to facilitate cellular uptake [13].

CS in combination with pectin has been widely explored for their benefit as colon-specific drug delivery system [14]. Apart from being biocompatible, less toxic, nonimmunogenic, and degradable by enzymes [15], CS can also be used in gene delivery system. Tremendous studies on graphene oxide (GO) have made it the gold approach in biomedicine applications. GO is a highly oxidised graphene form with oxygen functional groups on its surface. GO has been combined with CS to form a nanocarrier with better aqueous solubility and biocompatibility. In addition, it can exhibit powerful loading capacity besides having the ability to condense plasmid DNA into stable, nanosized complexes [16]. In an attempt to ensure that CS-GO-DsiRNA nanocomposites would be delivered to the target site successfully, pectin was used to coat the nanocomposites due to its unique property that will be degraded by colonic microflora. This property enables it to be used as a specific drug carrier to the colon [17]. Besides, it also displays antitumor activity [18] that can further enhance growth inhibition or cytotoxic effect in colon cancer cells.

In this study, water-soluble CS was synthesised from low molecular weight (LMW) CS to enhance its solubility, while GO was synthesised using Hummer's method from graphite flakes. Oxidation of graphite using oxidising agent will increase interplanar spacing between graphite layers, producing GO [19]. Later, DsiRNA was adsorbed onto CSGO nanocomposites. Pectin was utilised as coating agent to hinder premature DsiRNA release in gastric and intestinal fluids. To confirm successful synthesis of CS-GO-DsiRNApectin nanocomposites and their ability to load DsiRNA, physical characterization, structural analysis, and in vitro drug release study were conducted. The nanocomposites were also tested for their in vitro cytotoxic effect in normal and cancerous cell lines. Finally, silencing of VEGF gene by DsiRNA was determined using ELISA.

\section{Materials and Methods}

2.1. Materials. DsiRNA targeting VEGF gene $\left[5^{\prime}\right.$-rGrGrA rGrUrA rCrCrC rUrGrA rUrGrA rGrArU rCr- GrA rGrUA C- $3^{\prime}$ (sense strand) and $5^{\prime}$-rGrUrA rCrUrC rGrArU rCrUrC rArUrC rArGrG rGrUrA rCrUrC rCrCrA-3' (antisense strand)] was purchased from Integrated DNA Technologies, USA. Low molecular weight (LMW) CS of $190 \mathrm{kDa}$ with 75-85\% degree of deacetylation was purchased from SigmaAldrich (Ireland). Acetic acid and hydrochloric acid were obtained from R\&M Chemicals (UK). Hemicellulase enzyme from Aspergillus niger and pectin with $55-70 \%$ degree of esterification were obtained from Sigma-Aldrich, USA. $10 \mathrm{bp}$ DNA ladder was obtained from Invitrogen Corporation (Carlsbad), while sodium hydroxide was obtained from JIT (Baker Sweden). Deionised water was produced in the laboratory using Millipore Milli-Q. Phosphate-buffered saline (PBS) and dimethyl sulfoxide (DMSO) were obtained from Sigma-Aldrich (St. Louis, MO). Fetal bovine serum (FBS), Dulbecco's Modified Eagle's Medium (DMEM) High Glucose, Eagle's Minimum Essential Medium (EMEM), penicillin-streptomycin, MTT reagent, and trypsin-EDTA were purchased from Invitrogen (Carlsbad, CA). Caco2 cell line (colorectal adenocarcinoma cell derived from Homo sapiens, human) and CCD-18CO (normal colon cell derived from Homo sapiens, human) were obtained from the American Type Culture Collection (ATCC, Manassas, VA). Human VEGF ELISA kit was purchased from Sigma-Aldrich, USA. Acetic acid glacial, potassium dihydrogen phosphate, dipotassium hydrogen phosphate, sodium chloride $(\mathrm{NaCl})$, and sodium hydroxide $(\mathrm{NaOH})$ were purchased from $\mathrm{R} \& \mathrm{M}$ Chemicals (UK). All chemicals used were of analytical grade and were used as received.

\subsection{Methods}

2.2.1. Synthesis of Water-Soluble CS. 1g of LMW CS was dissolved in $2 \% \mathrm{v} / \mathrm{v}$ of acetic acid using a magnetic stirrer. The CS solution was adjusted to $\mathrm{pH} 4.5$ by adding few drops of $\mathrm{NaOH}$ and left overnight. A 20\% w/v hemicellulase enzyme solution was added to CS solution and the mixture was left in the water bath at $40^{\circ} \mathrm{C}$ for $6 \mathrm{~h} . \mathrm{pH}$ of the mixture was then adjusted to 5.5 by adding few drops of $\mathrm{NaOH}$ solution. After that, the mixture was boiled for $10 \mathrm{~min}$ to denature the enzyme. The upper layer of solution containing enzyme was removed manually by using a spatula until a concentrated 
solution formed. Then, the solution was frozen at $-80^{\circ} \mathrm{C}$ and it was lyophilised using a freeze dryer (ScanVac CoolSafe Freeze Drier, Lynge, Denmark) at $-110^{\circ} \mathrm{C}$ for one day to obtain water-soluble CS. It was then crushed into powdered form by using mortar and pestle. The functional groups of water-soluble CS were identified by using Fourier-Transform Infrared Spectrophotometer (FTIR) (Perkin-Elmer Spectrum 100 , Waltham, USA). $3 \mathrm{mg}$ of water-soluble CS and $300 \mathrm{mg}$ of dried IR-grade potassium bromide (previously heated for $2 \mathrm{~h}$ at $105^{\circ} \mathrm{C}$ ) were ground into powder to produce a thin disc. The sample was scanned at frequency range of 4000 to $400 \mathrm{~cm}^{-1}$.

2.2.2. Synthesis of GO Using Hummer's Method. An amount of $110 \mathrm{mg}$ graphite and an amount of $55 \mathrm{mg} \mathrm{NaNO} \mathrm{N}_{3}$ were mixed in $6 \mathrm{~mL}$ concentrated $\mathrm{H}_{2} \mathrm{SO}_{4}$ and the mixture was stirred overnight using a magnetic stirrer. An amount of $300 \mathrm{mg}$ $\mathrm{KMNO}_{4}$ was added and left overnight, while the conical flask was being surrounded by ice bath. Another $300 \mathrm{mg}$ of $\mathrm{KMNO}_{4}$ was added and left overnight on the next day. Ice bath was removed and it was replaced with water bath at $40^{\circ} \mathrm{C}$ overnight. Later, $7 \mathrm{~mL}$ of deionised water was added and heated in water bath at $98^{\circ} \mathrm{C}$ for $2 \mathrm{~h}$ until yellow-brownish solution was formed. $7 \mathrm{~mL}$ of $30 \% \mathrm{H}_{2} \mathrm{O}_{2}$ was added and the mixture was left for $1 \mathrm{~h}$ at $98^{\circ} \mathrm{C}$. After that, the mixture was left to cool down to room temperature and poured into centrifuge tube. The supernatant was removed and the pellet formed was resuspended with $10 \% \mathrm{HCl}$ and deionised water several times. Then, it was poured into dialysis bag for 5-7 days. The solution was frozen at $-80^{\circ} \mathrm{C}$ before it was lyophilised using a freeze drier (ScanVac CoolSafe Freeze Drier, Lynge, Denmark) at $-110^{\circ} \mathrm{C}$ for one day. The functional groups of GO were identified using FTIR (Perkin-Elmer Spectrum 100, Waltham, USA) as mentioned above.

\subsubsection{Preparation of DsiRNA-Loaded CS-GO Nanocomposites.} Water-soluble CS was dissolved in distilled water and stirred to produce $0.1 \% \mathrm{w} / \mathrm{v}$ of its solution. GO $0.25 \% \mathrm{w} / \mathrm{v}$ was added to CS solution separately and it was mixed continuously for $12 \mathrm{~h}$ using a magnetic stirrer. The resultant mixture was degassed in a sonicator bath for $30 \mathrm{~min}$. DsiRNA-loaded CSGO nanocomposites were prepared by adding $500 \mu \mathrm{L}$ of the nanocomposites solution to an equal volume of DsiRNA solution $(15 \mu \mathrm{g} / \mathrm{mL})$ in deionised water. The mixture was quickly mixed by inverting the reaction tube up and down for a few seconds and incubating for $30 \mathrm{~min}$ at room temperature before further analysis.

\subsubsection{Preparation of Pectin-Coated CS-GO Nanocomposites.}

Pectin powder was dissolved in deionised water at $70^{\circ} \mathrm{C}$ under magnetic stirring to produce $0.1 \% \mathrm{w} / \mathrm{v}$ pectin solution. $10 \mu \mathrm{L}$ of pectin solution was added to the DsiRNA-loaded CS-GO nanocomposites and the mixture was vortexed. The coated formulation was harvested by centrifugation (UNIVERSAL 320R Benchtop Centrifuge (Hettich Centrifuges, UK)) at $13000 \mathrm{rpm}$ for $1 \mathrm{~h}$ at $10^{\circ} \mathrm{C}$. The pellets were resuspended in deionised water.

\subsubsection{Determination of Particle Size, PDI, and Zeta Potential.} A volume of $1 \mathrm{~mL}$ nanocomposites suspension of CS-GO, CS-GO-DsiRNA, and pectin-coated CS-GO-DsiRNA was placed separately in a glass cuvette using a pipette prior to analysis. No dilution was done during the analysis. The particle size ( $z$-average), polydispersity index (PDI), and zeta potential of the nanocomposites were characterised in triplicate using Zetasizer ${ }^{\circledR}$ Nano ZS (Malvern Instruments, $\mathrm{UK})$. The measurements were performed at $25^{\circ} \mathrm{C}$ with a detection angle of $90^{\circ}$. All data are expressed as the mean \pm standard deviation (SD).

2.2.6. Determination of DsiRNA Entrapment Efficiency and Nanocomposites Yield. DsiRNA entrapment efficiency was obtained from determination of free DsiRNA concentration in supernatant recovered from centrifugation process using a UV-1061 UV-Visible Spectrophotometer (Shimadzu, Japan). Unloaded nanocomposites formulation was used as blank. Concentration of free DsiRNA was determined using Beer's Law $\left(A_{260}=\varepsilon C L\right)$ and calculations were done using the following equation:

$$
C=\frac{A}{\varepsilon L},
$$

where $C$ is the concentration of DsiRNA, $A_{260}$ is the extinction coefficient, and $L$ is the path length of the cuvette. Extinction coefficient of DsiRNA is $518500 \mathrm{~L}^{-1} \cdot \mathrm{cm}^{-1}$. The sample was measured in triplicate. The entrapment efficiency was calculated by using the following equation:

concentration of DsiRNA added - concentration of DsiRNA in supernatant concentration of DsiRNA added

The yield of nanocomposites was calculated by using the following equation:

$$
x=\frac{\text { mass of DsiRNA }- \text { nanocomposites }}{\text { total mass of composites and DsiRNA added }}
$$

2.2.7. Determination of DsiRNA Binding Efficiency. The binding efficiency of DsiRNA to the nanocomposites was determined by using $\mathrm{E}-\mathrm{Gel}^{\circledR} 4 \%$ agarose (GP) stained with ethidium bromide (Invitrogen, Israel). $20 \mu \mathrm{L}$ samples of nanocomposites were loaded into respective wells of the gel. Naked DsiRNA was used as positive control, while 10 bp DNA ladder was used as size reference. Electrophoresis was run for 
$30 \mathrm{~min}$. The migration of DsiRNA in form of bands in the gel was then visualised by using a real-time UV transilluminator (Invitrogen, USA).

2.2.8. Morphological Analysis. Morphological analysis of pectin-enveloped CS-GO nanocomposites was characterised by using a Transmission Electron Microscopy (TEM, Tecnai Spirit, FEI, Eindhoven, Netherlands). A drop of sample was placed on the copper microgrid that was stained by uranyl acetate and evaporated at room temperature $\left(25 \pm 2^{\circ} \mathrm{C}\right)$. It was viewed under a TEM for imaging of samples at different magnifying scales.

2.2.9. ATR-FTIR Spectroscopic Analysis. The Attenuated Total Reflectance FTIR spectra of pectin, CS-GO, and CS-GOpectin nanocomposites were recorded against the background by using a universal ATR sampling assembly (PerkinElmer Spectrum 100, Waltham, USA). For each sample, 16 scans were obtained at a resolution of $4 \mathrm{~cm}^{-1}$ in the range of 4000 to $400 \mathrm{~cm}^{-1}$. Meanwhile, LMW CS, water-soluble $\mathrm{CS}$, and GO powder were characterised by using FTIR Spectrophotometer (Perkin-Elmer Spectrum 100, Waltham, USA).

2.2.10. In Vitro Release Study. In vitro drug release study was performed in the simulated gastrointestinal (GI) condition; simulated gastric, intestinal, and colonic fluid (SGF, SIF, and SCF, resp.). Formulations containing $0.25 \mathrm{wt} \%$ GO coated with $0.1 \%$ and $0.2 \%$ pectin were used to determine the influence of pectin concentration on DsiRNA release. SGF was prepared by dissolving $2 \mathrm{~g}$ of $\mathrm{NaCl}$ in sufficient amount of distilled water. $7 \mathrm{~mL}$ of $0.1 \mathrm{~N} \mathrm{HCl}$ was added to the solution and the volume was made up to $1000 \mathrm{~mL}$ using distilled water. The $\mathrm{pH}$ was finally adjusted to 1.2 using $0.1 \mathrm{~N} \mathrm{HCl}$ or $0.1 \mathrm{~N} \mathrm{NaOH}$. Meanwhile, SIF was prepared by mixing solution containing $6.8 \mathrm{~g}$ of potassium dihydrogen phosphate in $250 \mathrm{~mL}$ distilled water with $72 \mathrm{~mL}$ of $0.2 \mathrm{M}$ $\mathrm{NaOH}$. Distilled water was added to make up to $1000 \mathrm{~mL}$ solution and the $\mathrm{pH}$ was adjusted to 6.8 by using $0.1 \mathrm{~N} \mathrm{HCl}$ or $0.2 \mathrm{M} \mathrm{NaOH}$. The SCF was prepared by mixing $250 \mathrm{~mL}$ of $0.2 \mathrm{M}$ dipotassium hydrogen phosphate with $28.5 \mathrm{~mL}$ of $0.2 \mathrm{M}$ $\mathrm{NaOH}$ and distilled water was added to make final volume of $1000 \mathrm{~mL}$. The $\mathrm{pH}$ of the solution was adjusted to $7.2 \mathrm{using}$ $0.1 \mathrm{~N} \mathrm{HCl}$ or $0.2 \mathrm{M} \mathrm{NaOH}$. For the first $2 \mathrm{~h}$, the in vitro release study was conducted in SGF ( $\mathrm{pH} 1.2)$ to follow the average gastric emptying time. The medium was then replaced with SIF at pH 6.8 (with addition of few drops of $\mathrm{NaOH}$ ). The study was continued for another $3 \mathrm{~h}$. After that, the medium was replaced with SCF at $\mathrm{pH} 7.2$ (with addition of few drops of $\mathrm{NaOH}$ ) in the presence of $0.3 \mathrm{~mL}$ pectinolytic enzyme and the study was extended for another $3 \mathrm{~h}$. Each formulation $(300 \mu \mathrm{L})$ was added to a dialysis tubing cellulose membrane (Sigma-Aldrich) and immersed in $50 \mathrm{~mL}$ of simulated fluids in a beaker. The beakers were placed in a shaker water bath (J.P Selecta) $\left(37 \pm 0.2^{\circ} \mathrm{C}\right)$ with horizontal shaking of $25 \mathrm{rpm}$. At predetermined time intervals, $4 \mathrm{~mL}$ of the simulated fluid was withdrawn and the concentration of DsiRNA released was measured using UV-Vis Spectrophotometry at $260 \mathrm{~nm}$.
To prevent sink condition, $4 \mathrm{~mL}$ of fresh medium was added to the beaker to replace the withdrawn fluid. The percentage of DsiRNA released was determined by using the following equation:

$$
\begin{aligned}
& \text { percentage of DsiRNA released (\%) } \\
& =\frac{\text { concentration of DsiRNA from withdrawn fluid }}{\text { concentration of DsiRNA added }} \\
& \quad \times 100 \%
\end{aligned}
$$

2.2.11. Cytotoxicity Study. Caco-2 cells (ATCC, Manassas, VA, USA) were cultured in DMEM medium at a cell density of $1 \times 10^{4}$ per well. The cells were supplemented with a medium containing $10 \%$ FBS and $1 \%$ penicillin-streptomycin and maintained at $37^{\circ} \mathrm{C}$ in a humidified $5 \% \mathrm{CO}_{2} / 95 \%$ air atmosphere. Meanwhile, CCD-18CO cells (ATCC, Manassas, VA, USA) were cultured in EMEM medium at a cell density of $5 \times 10^{3}$ per well. The cells were supplemented with a medium containing $10 \%$ FBS, $1 \%$ penicillin-streptomycin, and $1 \%$ sodium pyruvate and maintained at $37^{\circ} \mathrm{C}$ in a humidified $5 \%$ $\mathrm{CO}_{2} / 95 \%$ air atmosphere. After $24 \mathrm{~h}$ incubation of untreated cells, CS, pectin, GO, and CS-GO-DsiRNA nanocomposites, and CS-GO-DsiRNA nanocomposites coated with pectin at $37^{\circ} \mathrm{C}$, a final dilution of $1 / 10$ per cell volume of MTT reagent was added to all the wells, followed by incubation for $4 \mathrm{~h}$ prior to analysis. Then, the MTT containing medium was aspirated, and the formazan crystals formed by the living cells were dissolved in $200 \mu \mathrm{L}$ of DMSO solution. The absorbance of each sample at $570 \mathrm{~nm}$ was measured using a microplate reader (Varioskan Flash, Thermo Scientific, Waltham, MA, USA). The cytotoxicity effect was calculated as a percentage of the cell viability of untreated cells using the following equation:

$$
\text { cell viability }(\%)=\frac{\text { absorbance of treated cells }}{\text { absrbance of control cells }} \times 100 \text {. }
$$

2.2.12. ELISA Analysis of VEGF Protein. Caco-2 colon cancer cells were cultured in complete medium of DMEM (high glucose) which was supplemented with $10 \%$ fetal bovine serum and $1 \%$ penicillin-streptomycin. The cells were incubated in $25 \mathrm{~cm}^{2}$ plastic culture flasks at $37^{\circ} \mathrm{C}$ and $5 \%$ carbon dioxide $\left(\mathrm{CO}_{2}\right)$. When the cells achieved $70 \%$ confluency, they were then dissociated using $1 \mathrm{~mL}$ of $2.5 \mathrm{~g} / \mathrm{L}-T r y p s i n / 1 \mathrm{mmol} / \mathrm{L}-$ EDTA solution and incubated for 3-5 min at humidified $5 \% \mathrm{CO}_{2} / 95 \%$ air atmosphere. After trypsinization, the cells were suspended in $1 \mathrm{~mL}$ fresh medium and centrifuged for $3 \mathrm{~min}$ at $1000 \mathrm{~g}$. Then, the supernatant was discarded and the cell pellet was subsequently resuspended in $1 \mathrm{~mL}$ complete medium. Suspension density was measured using a haemocytometer. Once the cell density reached $1 \times 10^{5} / \mathrm{mL}$, $100 \mu \mathrm{L}$ of suspension was pipetted into each well. The cells were incubated for $24 \mathrm{~h}$ at $37^{\circ} \mathrm{C}$ with $5 \% \mathrm{CO}_{2}$. After $24 \mathrm{~h}$, the medium was changed to serum-free medium and Caco-2 colon cancer cells were exposed to pectin-enveloped CS-GO nanocomposites, DsiRNA-loaded CS-GO nanocomposites, pectin-enveloped DsiRNA-loaded CS-GO nanocomposites, 


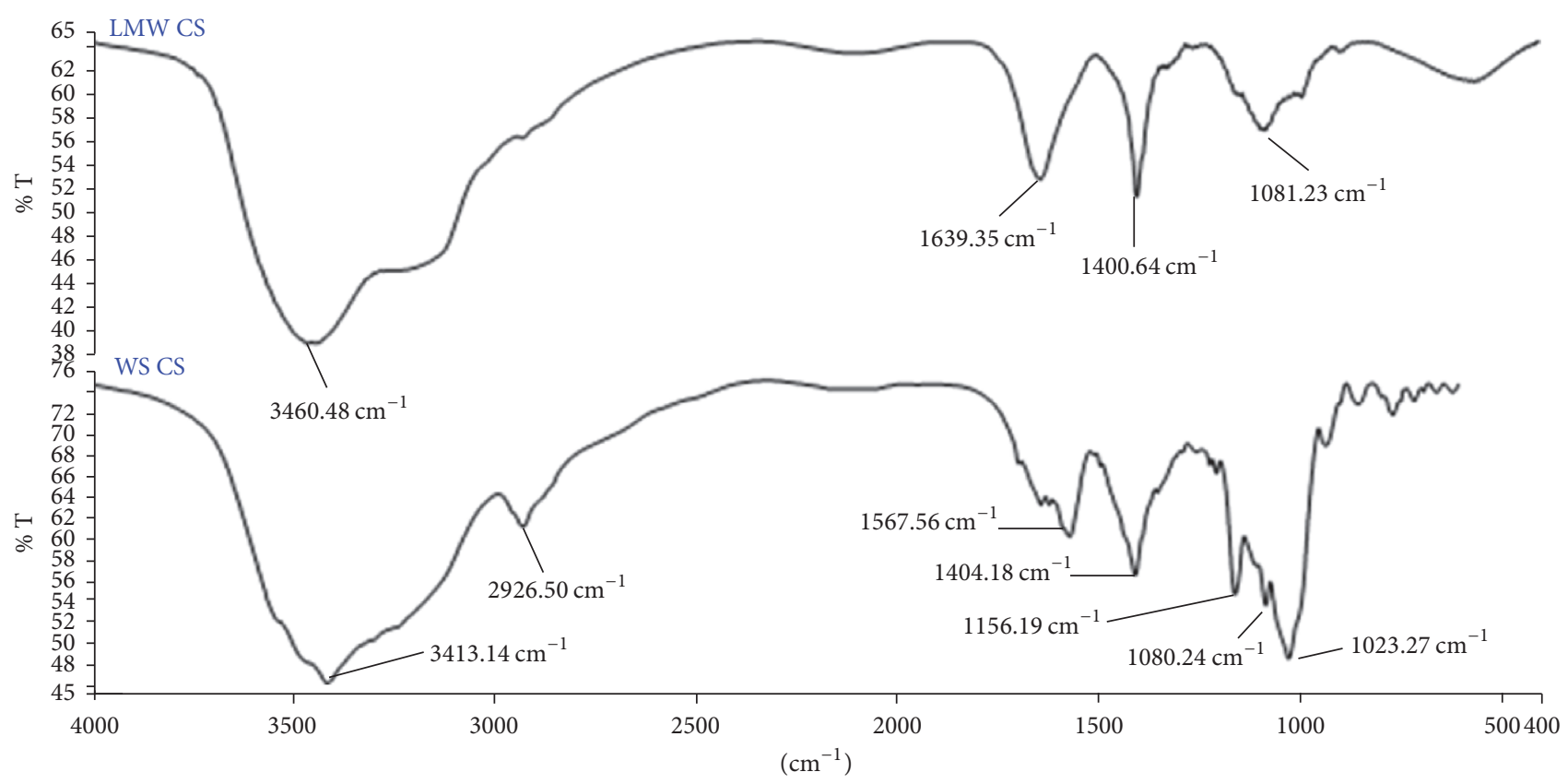

FIGURE 1: FTIR spectra of LMW CS and water-soluble CS.

and naked DsiRNA for $24 \mathrm{~h}$ at humidified $5 \% \mathrm{CO}_{2} / 95 \%$ air atmosphere. At the end of the exposure time, the culture media were collected and centrifuged to remove cell debris. The cell culture supernatants were used in ELISA assay. $100 \mu \mathrm{L}$ of each standard and cell culture supernatants were added to human EG-VEGF antibody-coated ELISA plate. The wells were covered and incubated in room temperature for $2.5 \mathrm{~h}$ with gentle shaking. The solution was discarded and washed with $300 \mu \mathrm{L}$ of $1 \mathrm{x}$ wash solution for each well for 4 times. After the last wash, the 96-well plate was inverted and blotted against clean paper towels. $100 \mu \mathrm{L}$ of biotinylated human EG-VEGF detection antibody was added to each well and incubated for $1 \mathrm{~h}$ at room temperature with gentle shaking. The solution was discarded and the washing step was repeated. Next, $100 \mu \mathrm{L}$ of HRP-Streptavidin solution was added to each well and incubated for $45 \mathrm{~min}$ at room temperature with gentle shaking. The solution was discarded and the washing step was repeated. Then, $100 \mu \mathrm{L}$ of $3,3^{\prime}, 5,5^{\prime}$-tetramethylbenzidine (TMB) One-Step Substrate Reagent was added to each well and incubated for $30 \mathrm{~min}$ at room temperature in the dark with gentle shaking. $50 \mu \mathrm{L}$ stop solution was added to each well and the plate was read at $450 \mathrm{~nm}$ immediately by a microplate reader (Varioskan Flash, Thermo Scientific, Waltham, MA, USA). The amounts of VEGF secreted from the untreated and treated cells were determined from the standard curve of optical density against known concentration of VEGF. All measurements were performed in triplicate and data are reported as mean \pm SD.

2.2.13. Statistical Analysis. The data obtained were shown as mean \pm standard deviation (SD). The data were further analysed using analysis of variance (one-way ANOVA, followed by Tukey's post hoc analysis) using SPSS 23.0 (SPSS
Inc., Chicago, IL, USA). $p$ value $<0.05$ was considered significantly statistically different among the groups tested.

\section{Results and Discussion}

3.1. Preparation of Water-Soluble CS. CS has been widely used for various purposes, especially in biomedical application, but it has limited capacity as it is insoluble in water and can only dissolve in acidic medium. In physiological pH 7.4, CS is insoluble. In order to ensure that it can be utilised across wide $\mathrm{pH}$ range, it is important to improve the solubility of CS. Thus, in current study, water-soluble CS has been synthesised from LMW CS by mean of enzymatic degradation. Katas and Alpar [20] reported that the use of LMW CS can generate smaller mean particle size as compared to high molecular weight (HMW) CS for the individual CS derivatives. This was also supported by Ilyina et al. [21] who reported that partially hydrolysed CS with LMW has better water solubility due to shorter chain lengths and free amino groups in $D$ glucosamine unit. The nature of the dissolution of CS was the degradation of intermacromolecular hydrogen bonds and interchain hydrogen bonds which modified the structure of $\mathrm{CS}$, reducing its crystallinity and unfolding its molecular chains [22]. The LMW CS powder is in yellowish color, whereas the water-soluble CS produced is in creamy white color powder form.

FTIR spectra of water-soluble CS and LMW CS are shown in Figure 1. The broad spectrum observed in LMW CS is $3460.48 \mathrm{~cm}^{-1}$, indicating the presence of $\mathrm{O}-\mathrm{H}$ stretching bond. There is a shift of band measured in water-soluble CS at $3413.14 \mathrm{~cm}^{-1}$, also representing $\mathrm{O}-\mathrm{H}$ stretching bond, but the peak width is narrower. C-H stretching can be seen in water-soluble CS at $2926.50 \mathrm{~cm}^{-1}$. The characteristic peaks at 
TABLE 1: Particle Size, PDI, and zeta potential of CS-GO nanocomposites before and after DsiRNA loading and pectin coating $(n=3)$.

\begin{tabular}{lcccccccc}
\hline \multicolumn{3}{c}{ Before DsiRNA loading } & \multicolumn{3}{c}{ After DsiRNA loading } & \multicolumn{3}{c}{ After pectin coating } \\
$\mathrm{PS}(\mathrm{nm}) \pm \mathrm{SD}$ & $\mathrm{PDI} \pm \mathrm{SD}$ & $\mathrm{ZP}(\mathrm{mV}) \pm \mathrm{SD}$ & $\mathrm{PS}(\mathrm{nm}) \pm \mathrm{SD}$ & $\mathrm{PDI} \pm \mathrm{SD}$ & $\mathrm{ZP}(\mathrm{mV}) \pm \mathrm{SD}$ & $\mathrm{PS}(\mathrm{nm}) \pm \mathrm{SD}$ & $\mathrm{PDI} \pm \mathrm{SD}$ & $\mathrm{ZP}(\mathrm{mV}) \pm \mathrm{SD}$ \\
\hline $308.2 \pm 85.9$ & $0.65 \pm 0.14$ & $+17.0 \pm 1.4$ & $125.2 \pm 15.6$ & $0.45 \pm 0.16$ & $+10.5 \pm 1.4$ & $554.4 \pm 126.6$ & $0.47 \pm 0.19$ & $-10.7 \pm 3.0$ \\
\hline
\end{tabular}

Keynotes: PS: particle size; PDI: polydispersity index; $\mathrm{ZP}=$ zeta potential.

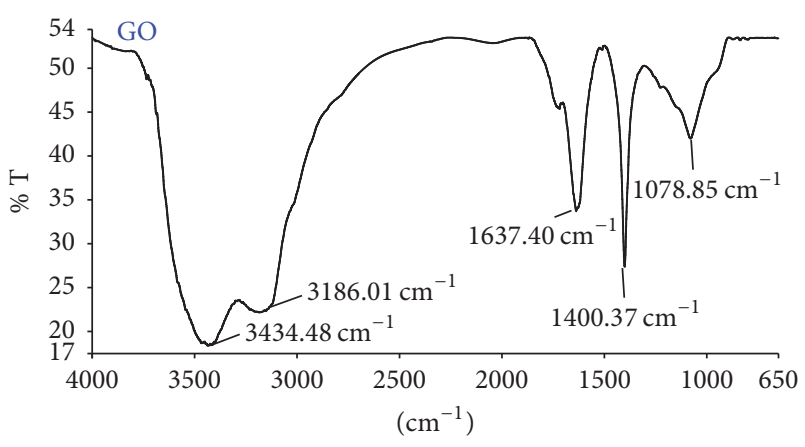

FIGURE 2: FTIR spectrum of GO prepared via Hummer's method.

$1639.35 \mathrm{~cm}^{-1}$ and $1400.64 \mathrm{~cm}^{-1}$ represent amide $1(\mathrm{C}=\mathrm{O})$ and amide III (complex vibration of NHCO group) bands of CS, respectively. Degree of deacetylation decreases as CS turns to be water-soluble and this is proven by the presence of peak at $1567.56 \mathrm{~cm}^{-1}$ due to contribution of amide II band. Stretching of ether (C-O-C) bridge is observed at $1156.19 \mathrm{~cm}^{-1}$. In LMW $\mathrm{CS}, \mathrm{C}-\mathrm{O}-\mathrm{C}$ stretching is assigned at $1081.23 \mathrm{~cm}^{-1}$ and there is a slight shift of the same functional group presence in water-soluble CS $\left(1080.24 \mathrm{~cm}^{-1}\right)$. Difference in FTIR spectra of LMW CS and water-soluble CS suggests that there is a cleavage of some glycosidic bonds introduced by hemicellulase enzyme. This reflects successful production of watersoluble CS from LMW CS.

3.2. Preparation of GO. GO was synthesised by using Hummer's method from graphite prior to preparation of CS-GO nanocomposites. In Hummer's method, graphite was being oxidised by an oxidising agent $\left(\mathrm{KMNO}_{4}\right)$, and increase in interplanar spacing between the layers of graphite would later produce GO [19]. In literature, the thickness of single-layer GO was reported in the range of 0.4 and $1.7 \mathrm{~nm}$ [23]. This variation in the thickness of the single graphene layers could be attributed to different measurement conditions, sample preparation procedures, or other laboratory conditions [24]. GO was then characterised by FT-IR analysis to investigate the bonding interactions in GO. Figure 2 depicts that GO has peak at $3434.48 \mathrm{~cm}^{-1}$ and it was attributed to $\mathrm{O}-\mathrm{H}$ stretching of $\mathrm{H}_{2} \mathrm{O}$ molecules absorbed during $\mathrm{GO}$ synthesis. Besides, $\mathrm{C}-\mathrm{H}$ stretching of aromatic group's peak is shown at $3186.01 \mathrm{~cm}^{-1}$. In addition, since GO has planar structure with bundle of aromatic rings, $\mathrm{C}=\mathrm{C}$ stretching of aromatic group can be observed at $1400.37 \mathrm{~cm}^{-1}$. The peak at $1078.85 \mathrm{~cm}^{-1}$ was assigned to $\mathrm{C}-\mathrm{O}$ stretching of ether functional group. This was supported by Paulchamy et al. [19] who also reported that $\mathrm{C}-\mathrm{O}$ bond was observed at $1081 \mathrm{~cm}^{-1}$, verifying existence of oxide functional groups after the oxidation process. Hence, GO was successfully synthesised from graphite by using Hummer's method.

3.3. Particle Size, Surface Charge, and PDI of Nanocomposites. In current study, concentration of CS at $0.1 \% \mathrm{w} / \mathrm{v}$ was used as it produced nanocomposites with smaller particle size compared to higher concentrations of CS $(0.2$ and $0.3 \% \mathrm{w} / \mathrm{v})$ (data was not shown). It was previously reported that lower concentrations of CS contributed to smaller particle size of nanoparticles owing to their low viscosity that produces efficient gelation procedure [25]. In preliminary study, formulation of $0.1 \% \mathrm{w} / \mathrm{v}$ CS and $0.25 \% \mathrm{w} / \mathrm{v}$ GO had been shown to produce nanocomposites with the most favorable physical characteristics (Supplementary 1 in Supplementary Material available online at https://doi.org/10.1155/2017/4298218). Furthermore, the formulation had shown the desired release profile of DsiRNA because it allowed low release of DsiRNA in the simulated stomach and intestine fluids but with high cumulative release in the simulated colon fluid (Supplementary 2).

Based on these results, CS-GO nanocomposites were prepared from $0.1 \% \mathrm{w} / \mathrm{v}$ CS and $0.25 \% \mathrm{w} / \mathrm{v}$ GO. Table 1 presents the mean particle size of CS-GO nanocomposites before and after DsiRNA loading and pectin coating. GO prepared from graphite powder using Hummer's method was mixed with CS and the mean particle size measured was $308.2 \pm 85.9 \mathrm{~nm}$. CS is positively charged due to protonated amine and it will interact electrostatistically with negatively charged carboxyl group and phenolic group of GO to form strong interaction of CS-GO nanocomposites. These functional groups form intermolecular hydrogen binding and initiate very fine codispersion in the molecular space [26].

Upon the addition of DsiRNA to CS-GO nanocomposites, there was a significant reduction in the mean particle size measured. The particle size reduced to $125.2 \pm 15.6 \mathrm{~nm}$ ( $p<0.05$, ANOVA followed by Tukey's post hoc analysis). This was expected to be due to the interaction of oppositely charged CS and DsiRNA molecules. Negatively charged backbone of DsiRNA allows electrostatic interaction with cationic CS-GO and this resulted in adsorption of DsiRNA to the nanocomposites which also condensed DsiRNA through neutralization into more compact shape. Furthermore, phosphate group of DsiRNA further increase negative charge of this nanocomposite which previously was contributed mainly by GO. As a result, more negative charges are able to neutralise the protonated amine group of CS and this can be proven by significant particle size reduction of CSGO-DsiRNA nanocomposites. Raja et al. [27] reported that smaller particle size of the DsiRNA-loaded formulations was due to less extended or denser arrangement of CS molecules. 


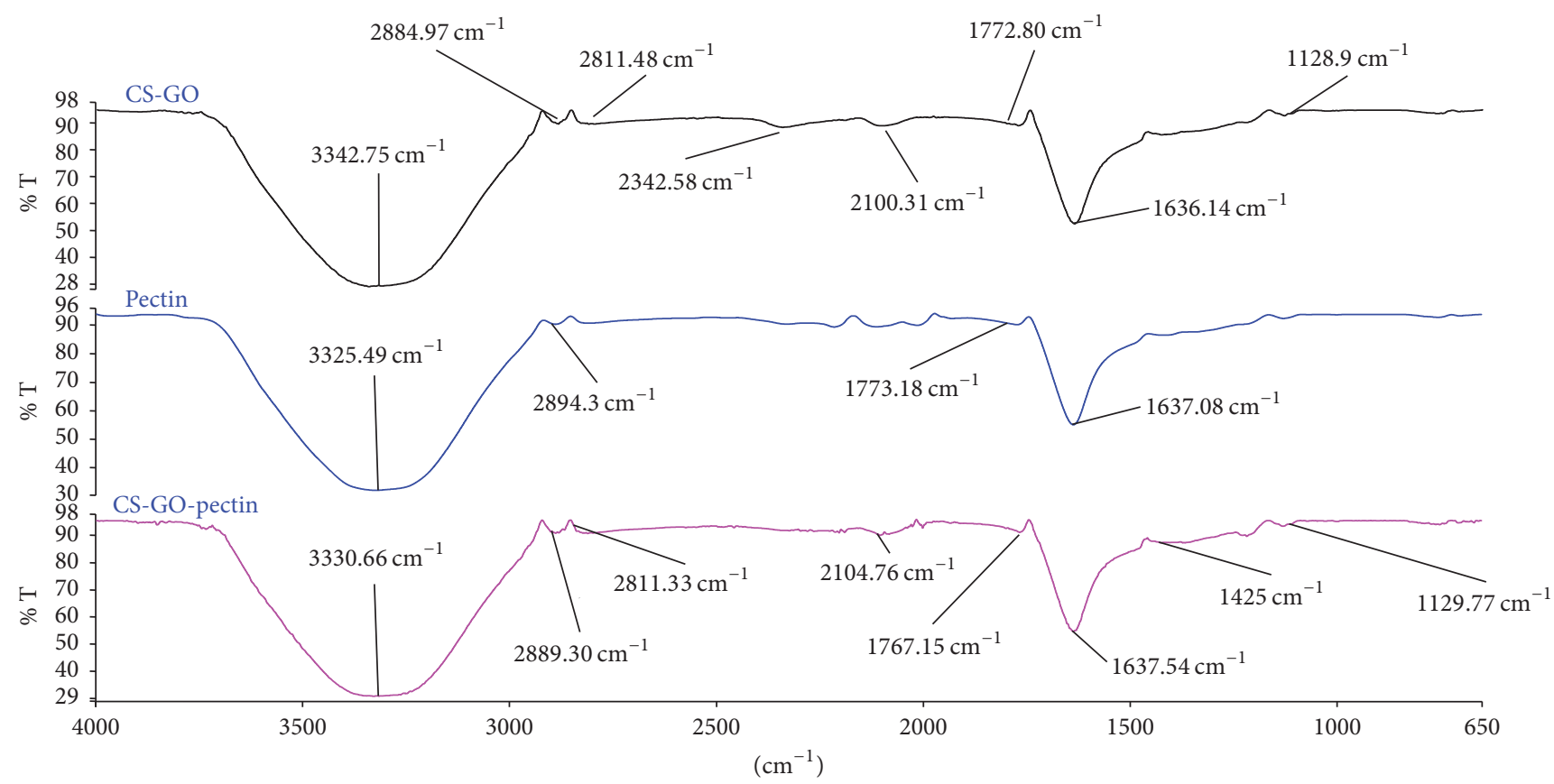

FIGURE 3: FTIR spectra of CS-GO, pectin, and CS-GO-pectin nanocomposites.

Even though CS is a well-known carrier for drug delivery, it has major drawback that is related to its fast dissolution in the stomach due to solubility in acidic condition [28]. To overcome this problem, an enteric coating is required to protect drug from being released in the stomach. Pectin has been used to coat the CS-GO-DsiRNA nanocomposites. The nanocomposite had increased particle size after coating with pectin. Polyelectrolyte complexes were formed when cationic amino groups on the $\mathrm{C} 2$ position of the repeating glucopyranose units of CS form electrostatic interaction with the negatively charged carboxyl groups of pectin [28]. The mean particle size of pectin-coated CS-GO-DsiRNA nanocomposites was $554.5 \pm 124.6 \mathrm{~nm}$. Larger size of nanocomposites after pectin coating was expected due to the presence of pectin layer on the surface of CS-GO nanocomposites. On the other hand, PDI value of CS-GO nanocomposites was $0.65 \pm 0.14$, which indicated that particle size was broadly distributed. Interestingly, PDI value of these nanocomposites reduced to $0.45 \pm 0.16$ after loading with DsiRNA, indicating homogeneity of the particles. After coating with pectin, PDI increased slightly to $0.47 \pm 0.19$ and it was considered within the acceptable range of narrow particle size distribution.

Zeta potential of CS-GO nanocomposites measured in this study was $+17.0 \pm 1.4 \mathrm{mV}$. CS is a very hydrophilic biopolymer and it has polycationic properties. As CS is mixed in aqueous medium, the functional group of $\mathrm{NH}_{2}$ and $\mathrm{OH}$ will be protonated to polycationic material. Meanwhile, surface of GO sheets is negatively charged when dispersed in water due to ionisation of carboxylic acid and phenolic hydroxyl groups on the GO sheets [26]. The net positive charge decreases to $+10.5 \pm 1.4$ after DsiRNA was loaded. Phosphate group of DsiRNA adsorbed onto the surface of CS-GO nanocomposites was attributed to the decrease in magnitude of zeta potential. The zeta potential of CS-GO-DsiRNA nanocomposites was further dropped and shifted from positive to negative value $(-10.7 \pm 3.0)$ after they were coated with pectin. This effect was owing to the negatively charged carboxylic acid $\left(\mathrm{COO}^{-}\right)$of pectin that forms electrostatic interaction with positively charged amino group $\left(\mathrm{NH}^{3+}\right)$ of CS [28]. This electrostatic interaction caused pectin to coat on CS-GO nanocomposites and led to reduction in zeta potential [29]. Upon addition of DsiRNA, followed by pectin, there were significant changes in zeta potential, indicating existence of interactions at each step in synthesising nanocomposites $(p<0.05$, ANOVA followed by Tukey's post hoc analysis).

3.4. ATR-FTIR Spectroscopic Analysis. FTIR peak spectrum comparison of pectin, CS-GO, and CS-GO-pectin nanocomposites provides further verification of successful configuration among them as shown in Figure 3. The presence of oxygen functional groups such as epoxy, hydroxyl, carbonyl, and carboxyl groups on the basal plane and edges can be used to characterise GO. Hydroxyl group (-O-H) stretching was observed at $3342.75 \mathrm{~cm}^{-1}, 3325.49 \mathrm{~cm}^{-1}$, and $3330.66 \mathrm{~cm}^{-1}$ in different formulations consisting of CS-GO, pectin, and CSGO-pectin, respectively. The peaks at $1773.18 \mathrm{~cm}^{-1}$ of pectin and $1772.80 \mathrm{~cm}^{-1}$ of CS-GO were assigned to $\mathrm{C}=\mathrm{O}$ stretching of carbonyl group. The peak then shifted to $1767.15 \mathrm{~cm}^{-1}$ for CS-GO-pectin nanocomposites, and this might be attributed to conjugation that moves absorption to a lower number. This was further confirmed when Bao et al. [16] reported that residual carbonyl moieties $(\mathrm{C}=\mathrm{O})$ on the basal plane and periphery of GO can be represented by small absorbance peak appearing at $1740 \mathrm{~cm}^{-1}$. The peak then shifted to 


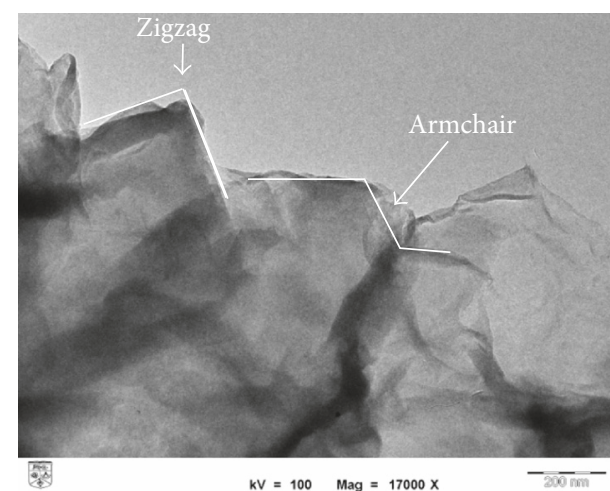

(a)

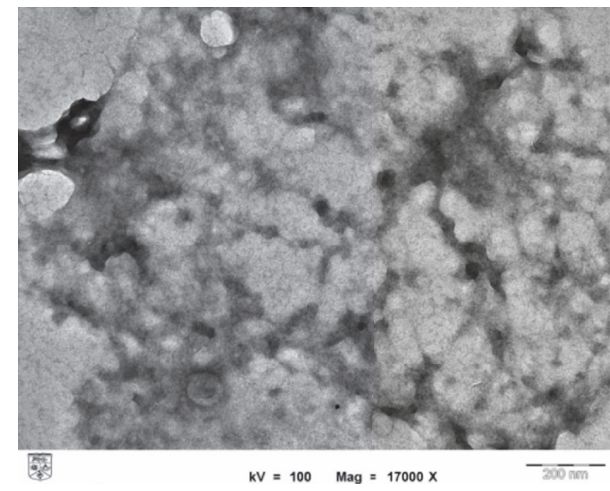

(c)

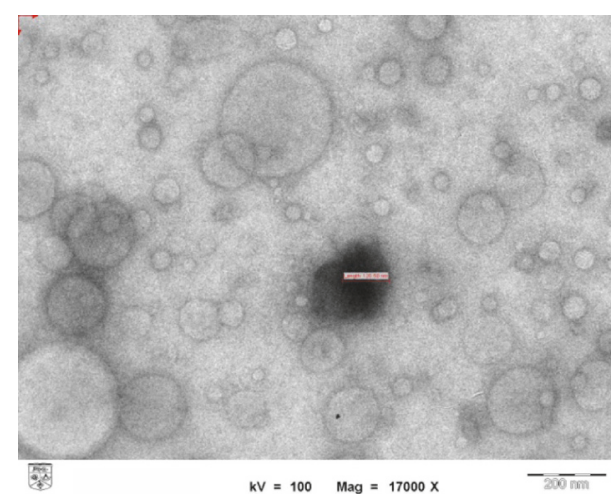

(b)

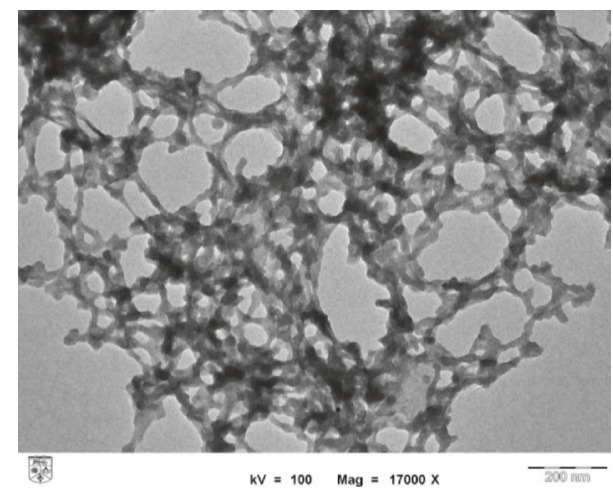

(d)

Figure 4: Morphology of GO (a), CS-GO nanocomposites (b), CS-GO-DsiRNA nanocomposites (c), and pectin-coated CS-GO-DsiRNA nanocomposites (d) at magnification of 17,000x. TEM micrograph of GO shows "armchair" and "zigzag" configurations.

$1767.15 \mathrm{~cm}^{-1}$ for CS-GO-pectin nanocomposites, and this might be attributed to conjugation that moved absorption to a lower number. Amine group characterised by $\mathrm{C}-\mathrm{N}$ stretching in CS-GO and also CS-GO-pectin nanocomposites can be seen clearly at $1128.92 \mathrm{~cm}^{-1}$ and $1129.77 \mathrm{~cm}^{-1}$, respectively.

3.5. Morphological Analysis. The morphology of GO, CSGO, CS-GO loaded with DsiRNA, and pectin-coated CS-GODsiRNA nanocomposites was investigated using TEM that illustrates nanoscale visualisation of an individual particle. Most importantly, TEM can provide information of both particle size and morphology of the nanoparticles. GO analysed under an electron microscope appeared to be in layers of lateral dimension sheets with sharp edges (Figure 4(a)). It was reported that GO sheets exist with very sharp edges and flat surfaces [16] that coincided with the GO produced in current study. Besides, large surface area of GO sheets is usually utilised as support for growth and stabilisation of nanoparticles [30].

Upon mixing GO into CS solution, irregular shape of nanocomposites was observed as shown in Figure 4(b). Similar morphology was also reported by Bao et al. [16], in which CS-GO appear to be coarse and some protuberances could be seen on the surface, which mainly were generated from the polymer wrapping and folding. Figure 4(c) shows formation of small, rounded, and smooth surface of CSGO-DsiRNA nanocomposites. Small particle size reflects that DsiRNA is well adsorbed onto CS-GO nanocomposites. However, after the nanocomposites were coated with pectin, they appeared to fuse with one another and form aggregates. This could be seen from Figure 4(d). Generally, the estimated sizes for CS-GO, CS-GO-DsiRNA, and pectin-coated CSGO-DsiRNA nanocomposites were 2.6-, 2.8-, and 5.5-fold smaller than those measured using dynamic light scattering (DLS). The difference in measured particle size using TEM and DLS might be attributed to different principles applied. The equivalent diameter used in particle size analysis for TEM and DLS is projected area and hydrodynamic diameter of diffusion area, respectively. Despite that, DLS provides a more accurate measurement as it represents the whole sample.

\subsection{DsiRNA Entrapment and Binding Efficiencies and Nano-} composites Yield. High entrapment efficiency of $92.6 \pm 3.9 \%$ was measured for CS-GO-DsiRNA (0.1\% w/v CS and $0.25 \%$ w/v GO) nanocomposites, besides its high nanocomposites yield $(77.1 \pm 4.6 \%)$, which is considered suitable for delivering a therapeutically active dose [31]. High entrapment efficiency plays significant role in ensuring that drug is being delivered to its target successfully. CS-GO sheets have powerful capacity to entrap plasmid DNA to form compact complexes [16]. Besides, graphene nanosheets have wide surface area that 


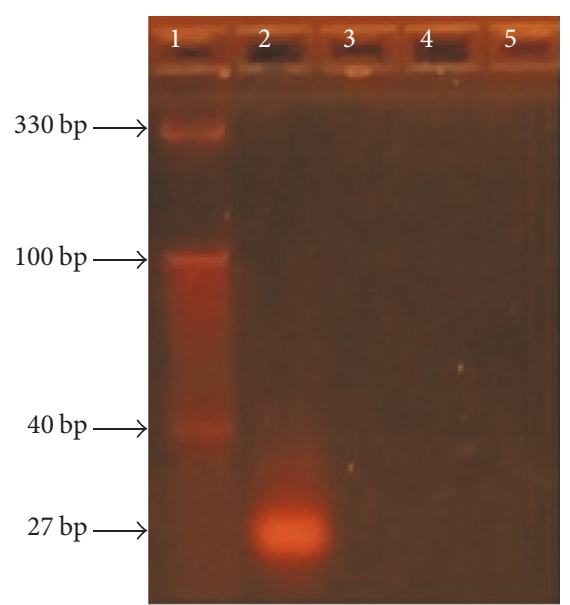

(1) DNA ladder (10 bp)

(2) Naked DsiRNA

(3) CS-GO-DsiRNA

(4) Pectin-coated DsiRNA CS-GO nanocomposites $(0.1 \% \mathrm{w} / \mathrm{v}$ pectin $)$

(5) Pectin-coated DsiRNA CS-GO nanocomposites $(0.2 \% \mathrm{w} / \mathrm{v}$ pectin $)$

FIgURE 5: Binding efficiency of CS-GO-DsiRNA nanocomposites.

enables them to be functionalised maximally besides having great loading capacity. They also allowed encapsulation of molecules together for protection purpose and sustained release of loaded molecules which becomes a trend in current delivery applications [3]. Pectin was further added as a coating agent to ensure that DsiRNA was entrapped on the surface of CS-GO sheets and protected from the harsh environment of the stomach and small intestine. Moreover, the coating has no significant effect on the entrapment efficiency as the percent was maintained after coating with $0.1 \%$ pectin (\% EE $=90.2 \pm 5.4$, refer to Supplementary 1). Similar finding was observed for the yield of nanocomposites after coating with pectin (yield $=74.9 \pm 1.4 \%$ ). On the other hand, Figure 5 shows the absence of a trailing band of DsiRNA. This indicated that DsiRNA has strong binding interaction with CS-GO nanocomposites and it was well protected by pectin layer. These results suggested that pectin coating did not affect the binding efficiency of anionic DsiRNA with cationic CS-GO nanocomposites or causing premature release of DsiRNA. The results also further supported the finding of high DsiRNA entrapment efficiency for CS-GO. DsiRNA was found to be efficiently and tightly bound to CS nanoparticles as reported by Raja et al. [27]. However, the binding of DsiRNA can be reversed and it will be released when the polymeric matrix degrades [27]. In this situation, dissociation of pectin by the action of pectinase enzyme will also allow the release of DsiRNA in colon.

3.7. In Vitro Drug Release. Two formulations with constant GO wt $\%$ but different pectin concentrations were tested to demonstrate the influence of pectin on drug release (Figure 6). From the results obtained, the amount of DsiRNA

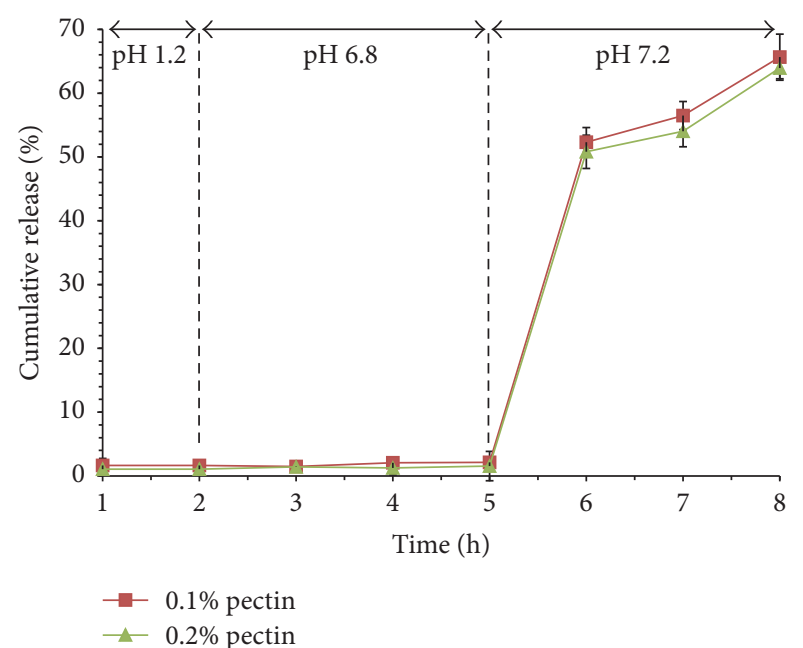

FIGURE 6: Release profile of DsiRNA from pectin-enveloped CS-GO nanocomposites of different pectin concentration at different $\mathrm{pHs}$ $(1.2,6.8$, and 7.2) $(n=3)$. CS-GO nanocomposites were prepared using $0.1 \% \mathrm{w} / \mathrm{v}$ CS and $0.25 \% \mathrm{GO}$.

released was slightly higher in formulation coated with $0.1 \%$ $\mathrm{w} / \mathrm{v}$ pectin. It could be due to the surface of nanocomposite that was coated with lower amount of pectin and hence would be degraded faster than the formulation with higher pectin amount. Nevertheless, the difference was insignificant ( $p>0.05$, independent $t$-test). In contrast to that, a study conducted by Kushwaha et al. [32] demonstrated that the rate of drug released was mainly affected by pectin concentration used to coat the drug. The percentage of cumulative release of DsiRNA in SGF ( $\mathrm{pH} 2$ ) for $2 \mathrm{~h}$ was approximately $1 \%$ indicating a slow drug release pattern. Moving to SIF $(\mathrm{pH}$ 6.8 ), the percentage increased to approximately $2 \%$. Only small amount of DsiRNA was detected in the medium owing to the properties of pectin which is insoluble in acidic $\mathrm{pH}$ [32]. In contrast to that, a remarkable increase in release of DsiRNA was observed in SCF ( $\mathrm{pH} 7.2$ ) (from 2\% to $\sim 52 \%$ ). The maximum release was achieved after $3 \mathrm{~h}$ in SCF and the percent measured was $65.6 \%$ and $63.9 \%$ for $0.1 \%$ and $0.2 \% \mathrm{w} / \mathrm{v}$ pectin, respectively. The exposure to SCF and pectinase enzyme causes pectin to be degraded, thus releasing greater amount of DsiRNA. Inside the human colon, numerous bacteria secrete enzymes that break down the polymer backbone, resulting in decrease in its molecular weight, thus losing their mechanical strength and ending up with the release of drug entity. Besides pectin, CS is also able to shield drugs from harsh stomach and small intestine environment [33]. A successful colon drug delivery requires the triggering mechanism in the delivery system that only responds to the physiological conditions particular to the colon [34]. The in vitro release study showed that pectin was not much degraded in the stomach and small intestine but was susceptible to enzymatic breakdown in the colon by the natural microflora. Therefore, it is a suitable candidate to deliver and target drugs to the colon. A high release rate of DsiRNA in SCF with the presence of pectinolytic enzyme 


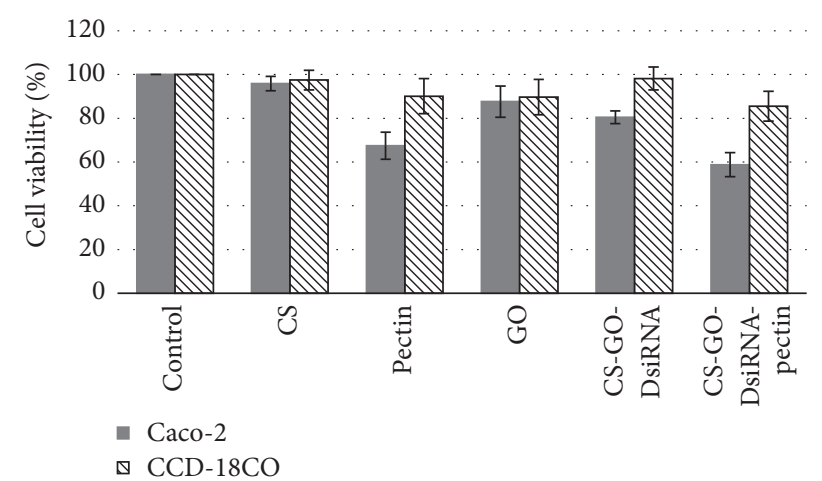

Figure 7: Cytotoxicity effect of Caco-2 and CCD-18CO cells exposed to nanocomposites and their parent compounds at $24 \mathrm{~h}$ after incubation $(n=3)$.

pointed out the ability of pectin coating to hinder premature release of drug in upper GI tract.

3.8. Cell Growth Inhibition Effect and VEGF Downregulation. The cytotoxic effects of nanocomposites developed in this study were determined in normal and cancerous cell lines. The cytotoxic effects of CS-GO-DsiRNA nanocomposites coated with pectin and its individual component were investigated against human colon adenocarcinoma cells (Caco-2 cells) and human colon normal cells (CCD-18CO cells). The percentage of cell viability of nanocomposites in Caco-2 and CCD-18CO is shown in Figure 7. CS-GO-DsiRNA nanocomposites coated with pectin caused significant reduction in cell viability towards Caco-2 cells in which the percent reduced to almost half from the untreated cells $(p<0.05$, ANOVA followed by Tukey's post hoc analysis). In normal cell line, the cell viability recorded was $85 \%$ and it was higher than in cancer cells.

Moreover, 33\% loss of cell viability was measured after Caco-2 cells were treated with pectin followed by $13 \%$ loss by GO. Apart from being utilised as specific drug carrier to the colon, pectin also has been studied for its antitumor activity. According to Glinsky and Raz [18], antitumor activity of pectin was attributed to abundant $\beta$-galactose present in modified citrus pectin (MCP). The primary mechanism of action for MCP is by inhibiting a $\beta$-galactoside binding protein galectin-3 (Gal-3), which is responsible for angiogenic activity. Interestingly, induction of pectin in healthy cells, CCD-18CO, did not display any reduction in cell viability. Similar finding was reported elsewhere [2] in which pectin acts more destructively against Caco- 2 colon cancer cells but not against healthy VERO cells. The selective killing effect towards cancer cells makes it a precious natural polysaccharide. In addition, GO used in this study has also been shown to enhance cytotoxicity effect displayed by final formulation. Recent study claimed that negatively charged oxygen group of GO can form electrostatic interaction with positively charged lipids present on cell membranes, thus destroying the cell membrane [30]. In contrast to that, GO did not cause decreased cell viability in normal colon cells. This might be due to low amount of GO which was used

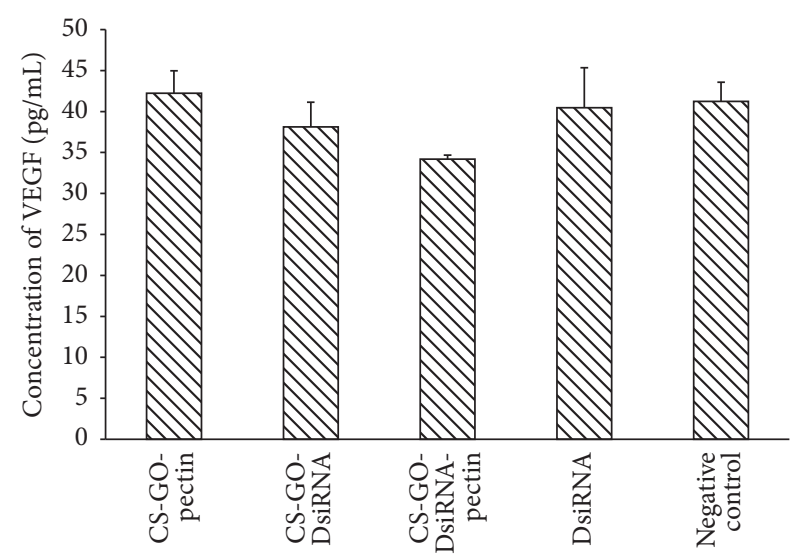

FIGURE 8: Human EG-VEGF level of Caco-2 cells treated with pectin-coated CS-GO, CS-GO-DsiRNA, and pectin-coated CS-GODsiRNA nanocomposites and naked DsiRNA and nontreated cells (negative control) $(n=3)$.

in this assay $(250 \mu \mathrm{g} / \mathrm{mL})$. Insignificant loss of peritoneal macrophages viability was also reported previously when the cells were exposed to GO at low concentration [30]. In addition, both cell lines treated with uncoated formulation did not show any decrease in cell viability. The absence of pectin that is responsible for enhancing antitumor activity further eliminates the inhibitory effect of DsiRNA and GO.

In this study, DsiRNA targeting VEGF gene was used as the gene is excessively expressed in Caco-2 cells. It was reported that increased metastasis risk in colon cancer correlates well with VEGF expression [35]. VEGF is most commonly associated with tumor angiogenesis which involved tumor growth and metastasis in human colon cancer [36] and it is supported elsewhere [37]. The VEGF concentration level in Caco-2 colon cancer cells was determined by ELISA after being treated with pectin-enveloped CS-GO, DsiRNA-loaded CS-GO, and pectin-enveloped CS-GO-DsiRNA nanocomposites and naked DsiRNA for $24 \mathrm{~h}$. From Figure 8, there was no significant change in VEGF concentration level observed after Caco-2 colon cancer cells were treated with pectin-enveloped CS-GO (blank nanocomposites) and naked DsiRNA for $24 \mathrm{~h}$ as compared to negative control (untreated cells), indicating the absence of a gene silencing effect. However, a lower VEGF concentration level was significantly ( $p$ value $<0.05$ ) measured for the cells treated with pectinenveloped DsiRNA-loaded CS-GO nanocomposites after 24 incubation as shown in Figure 8. This finding demonstrated that pectin was able to protect and facilitate DsiRNA to accumulate at and act on the site of action which subsequently resulted in significant decrease of VEGF level [38].

\section{Conclusions}

In summary, pectin-coated CS-GO-DsiRNA nanocomposites were successfully developed via electrostatic interaction. FTIR analysis further confirmed successful synthesis of GO and CS-GO-pectin nanocomposites. The results revealed significant difference in particle size at each stage 
of nanocomposites preparation which signifies production of CS-GO-DsiRNA-pectin nanocomposites. Moreover, high entrapment efficiency of these nanocomposites indicated that DsiRNA was effectively adsorbed onto CS-GO carrier. CSGO-DsiRNA nanocomposites coated with pectin selectively killed cancer cells, which could be a promising therapeutic agent for cancer treatment. Moreover, VEGF concentration level significantly decreased after $24 \mathrm{~h}$ incubation with the pectin-enveloped CS-GO-DsiRNA nanocomposites; thus it indicated the ability of nanocomposites to deliver DsiRNA effectively into the cells and subsequently cause gene silencing on the target gene. Further studies in animal model in vivo are necessary to study the safety and efficacy of CS-GO-DsiRNA nanocomposites coated with pectin.

\section{Conflicts of Interest}

The authors report no conflicts of interest in this work.

\section{Acknowledgments}

The authors greatly acknowledge Universiti Kebangsaan Malaysia (UKM) (GUP-2014-061) for supporting and providing resources to complete this research project.

\section{References}

[1] International Agency for Research on Cancer, "Estimated cancer incidence, mortality, and prevalence worldwide in globocan," World Health Organization 2012, http://www.iarc.fr/.

[2] E. A. M. S. Almeida, S. P. Facchi, A. F. Martins et al., "Synthesis and characterization of pectin derivative with antitumor property against Caco- 2 colon cancer cells," Carbohydrate Polymers, vol. 115, pp. 139-145, 2015.

[3] M. S. Draz, B. A. Fang, P. Zhang et al., "Nanoparticle-mediated systemic delivery of siRNA for treatment of cancers and viral infections," Theranostics, vol. 4, no. 9, pp. 872-892, 2014.

[4] S. Kulisch, T. Esch, C. Whitman-Guliaev, and T. Rubio, "Dicer-substrate siRNA technology: advances in siRNA designs improve gene-specific silencing," BioRadiations, vol. 120, pp. 16, 2006.

[5] M. Amarzguioui and J. J. Rossi, "Principles of Dicer substrate (D-siRNA) design and function," RNAi: Design and Application, pp. 3-10, 2008.

[6] M. Izquierdo, "Short interfering RNAs as a tool for cancer gene therapy," Cancer Gene Therapy, vol. 12, no. 3, pp. 217-227, 2005.

[7] N. Yamagishi, S. Teshima-Kondo, K. Masuda et al., "Chronic inhibition of tumor cell-derived VEGF enhances the malignant phenotype of colorectal cancer cells," BMC Cancer, vol. 13, article 229, 2013.

[8] A. Ahluwalia, M. K. Jones, S. Szabo, and A. S. Tarnawski, "Aberrant, ectopic expression of VEGF and VEGF receptors 1 and 2 in malignant colonic epithelial cells. Implications for these cells growth via an autocrine mechanism," Biochemical and Biophysical Research Communications, vol. 437, no. 4, pp. 515-520, 2013.

[9] J. Conde, A. Ambrosone, Y. Hernandez et al., "15 years on siRNA delivery: beyond the state-of-the-art on inorganic nanoparticles for RNAi therapeutics," Nano Today, vol. 10, no. 4, pp. 421-450, 2015.
[10] R. Kanasty, J. R. Dorkin, A. Vegas, and D. Anderson, "Delivery materials for siRNA therapeutics," Nature Materials, vol. 12, pp. 967-977, 2013.

[11] A. Falamarzian, X.-B. Xiong, H. Uludag, and A. Lavasanifar, "Polymeric micelles for siRNA delivery," Journal of Drug Delivery Science and Technology, vol. 22, no. 1, pp. 43-54, 2012.

[12] R. K. Tekade, M. Tekade, P. Kesharwani, and A. D'Emanuele, "RNAi-combined nano-chemotherapeutics to tackle resistant tumors," Drug Discovery Today, vol. 21, no. 11, pp. 1761-1774, 2016.

[13] Y. Ping, C. D. Liu, G. P. Tang et al., "Functionalization of chitosan via atom transfer radical polymerization for gene delivery," Advanced Functional Materials, vol. 20, pp. 3106-3116, 2010.

[14] V. R. Sinha and R. Kumria, "Polysaccharides in colon-specific drug delivery," International Journal of Pharmaceutics, vol. 224, no. 1-2, pp. 19-38, 2001.

[15] F. Liu and L. Huang, "Development of non-viral vectors for systemic gene delivery," Journal of Controlled Release, vol. 78, no. 1, pp. 259-266, 2002.

[16] H. Q. Bao, Y. Z. Pan, Y. Ping et al., "Chitosan-functionalized graphene oxide as a nanocarrier for drug and gene delivery," Small, vol. 7, no. 11, pp. 1569-1578, 2011.

[17] E. Bernstein, A. A. Caudy, S. M. Hammond, and G. J. Hannon, "Role for a bidentate ribonuclease in the initiation step of RNA interference," Nature, vol. 409, no. 6818, pp. 363-366, 2001.

[18] V. V. Glinsky and A. Raz, "Modified citrus pectin anti-metastatic properties: one bullet, multiple targets," Carbohydrate Research, vol. 344, no. 14, pp. 1788-1791, 2009.

[19] B. Paulchamy, G. Arthi, and B. Lignesh, "A simple approach to stepwise synthesis of graphene oxide nanomaterial," Journal of Nanomedicine \& Nanotechnology, vol. 6, no. 1, article 1, 2015.

[20] H. Katas and H. O. Alpar, "Development and characterisation of chitosan nanoparticles for siRNA delivery," Journal of Controlled Release, vol. 115, no. 2, pp. 216-225, 2006.

[21] A. V. Ilyina, N. Y. Tatarinova, and V. P. Varlamov, "The preparation of low-molecular-weight chitosan using chitinolytic complex from streptomyces kurssanovii," Process Biochemistry, vol. 34, no. 9, pp. 875-878, 1999.

[22] S. Lu, X. Song, D. Cao, Y. Chen, and K. Yao, "Preparation of water-soluble chitosan," Journal of Applied Polymer Science, vol. 91, no. 6, pp. 3497-3503, 2004.

[23] C. J. Shearer, A. D. Slattery, A. J. Stapleton, J. G. Shapter, and C. T. Gibson, "Accurate thickness measurement of graphene," Nanotechnology, vol. 27, no. 12, Article ID 125704, 2016.

[24] P. Nemes-Incze, Z. Osváth, K. Kamarás, and L. P. Biró, “Anomalies in thickness measurements of graphene and few layer graphite crystals by tapping mode atomic force microscopy," Carbon, vol. 46, no. 11, pp. 1435-1442, 2008.

[25] S. S. Omar Zaki, H. Katas, and Z. A. Hamid, "Lineage-related and particle size-dependent cytotoxicity of chitosan nanoparticles on mouse bone marrow-derived hematopoietic stem and progenitor cells," Food and Chemical Toxicology, vol. 85, pp. 3144, 2015.

[26] N. I. Syuhada, N. M. Huang, S. Vijay Kumar et al., "Enhanced mechanical properties of chitosan/edta-go nanocomposites thin films," Sains Malaysiana, vol. 43, no. 6, pp. 851-859, 2014.

[27] M. A. G. Raja, H. Katas, Z. Abd Hamid, and N. A. Razali, "Physicochemical properties and in vitro cytotoxicity studies of chitosan as a potential carrier for dicer-substrate siRNA," Journal of Nanomaterials, vol. 2013, Article ID 653892, 10 pages, 2013. 
[28] J. H. Hamman, "Chitosan based polyelectrolyte complexes as potential carrier materials in drug delivery systems," Marine Drugs, vol. 8, no. 4, pp. 1305-1322, 2010.

[29] R. K. Dutta and S. Sahu, "Development of diclofenac sodium loaded magnetic nanocarriers of pectin interacted with chitosan for targeted and sustained drug delivery," Colloids and Surfaces B: Biointerfaces, vol. 97, pp. 19-26, 2012.

[30] L. A. V. de Luna, A. C. M. Moraes, S. R. Consonni et al., "Comparative in vitro toxicity of a graphene oxide-silver nanocomposite and the pristine counterparts toward macrophages," Journal of Nanobiotechnology, vol. 14, no. 1, article 1, 2016.

[31] B. T. AL-Quadeib, M. A. Radwan, L. Siller, B. Horrocks, and M. C. Wright, "Stealth amphotericin B nanoparticles for oral drug delivery: in vitro optimization," Saudi Pharmaceutical Journal, vol. 23, no. 3, pp. 290-302, 2015.

[32] P. Kushwaha, S. Fareed, S. Nanda, and A. Mishra, "Design \& fabrication of tramadol HCL loaded multiparticulate colon targeted drug delivery system," Journal of Chemical and Pharmaceutical Research, vol. 3, no. 5, pp. 584-595, 2011.

[33] A. K. Philip and B. Philip, "Colon targeted drug delivery systems: a review on primary and novel approaches," Oman Medical Journal, vol. 25, no. 2, pp. 70-78, 2010.

[34] L. Yang, J. S. Chu, and J. A. Fix, "Colon-specific drug delivery: new approaches and in vitro/in vivo evaluation," International Journal of Pharmaceutics, vol. 235, no. 1-2, pp. 1-15, 2002.

[35] Y. Takahashi, Y. Kitadai, C. D. Bucana, K. R. Cleary, and L. M. Ellis, "Expression of vascular endothelial growth factor and its receptor, KDR, correlates with vascularity, metastasis, and proliferation of human colon cancer," Cancer Research, vol. 55, no. 18, pp. 3964-3968, 1995.

[36] L. M. Ellis, Y. Takahashi, W. Liu, and R. M. Shaheen, "Vascular endothelial growth factor in human colon cancer: biology and therapeutic implications," Oncologist, vol. 5, no. 1, pp. 11-15, 2000.

[37] L. F. Brown, B. Berse, R. W. Jackman et al., "Expression of vascular permeability factor (vascular endothelial growth factor) and its receptors in adenocarcinomas of the gastrointestinal tract," Cancer Research, vol. 53, no. 19, pp. 4727-4735, 1993.

[38] M. A. G. Raja, H. Katas, and Z. Abd Hamid, "Penetration and silencing activity of VEGF dicer substrate siRNA vectorized by chitosan nanoparticles in monolayer culture and a solid tumor model in vitro for potential application in tumor therapy," Journal of Nanomaterials, vol. 2016, Article ID 7201204, 16 pages, 2016. 

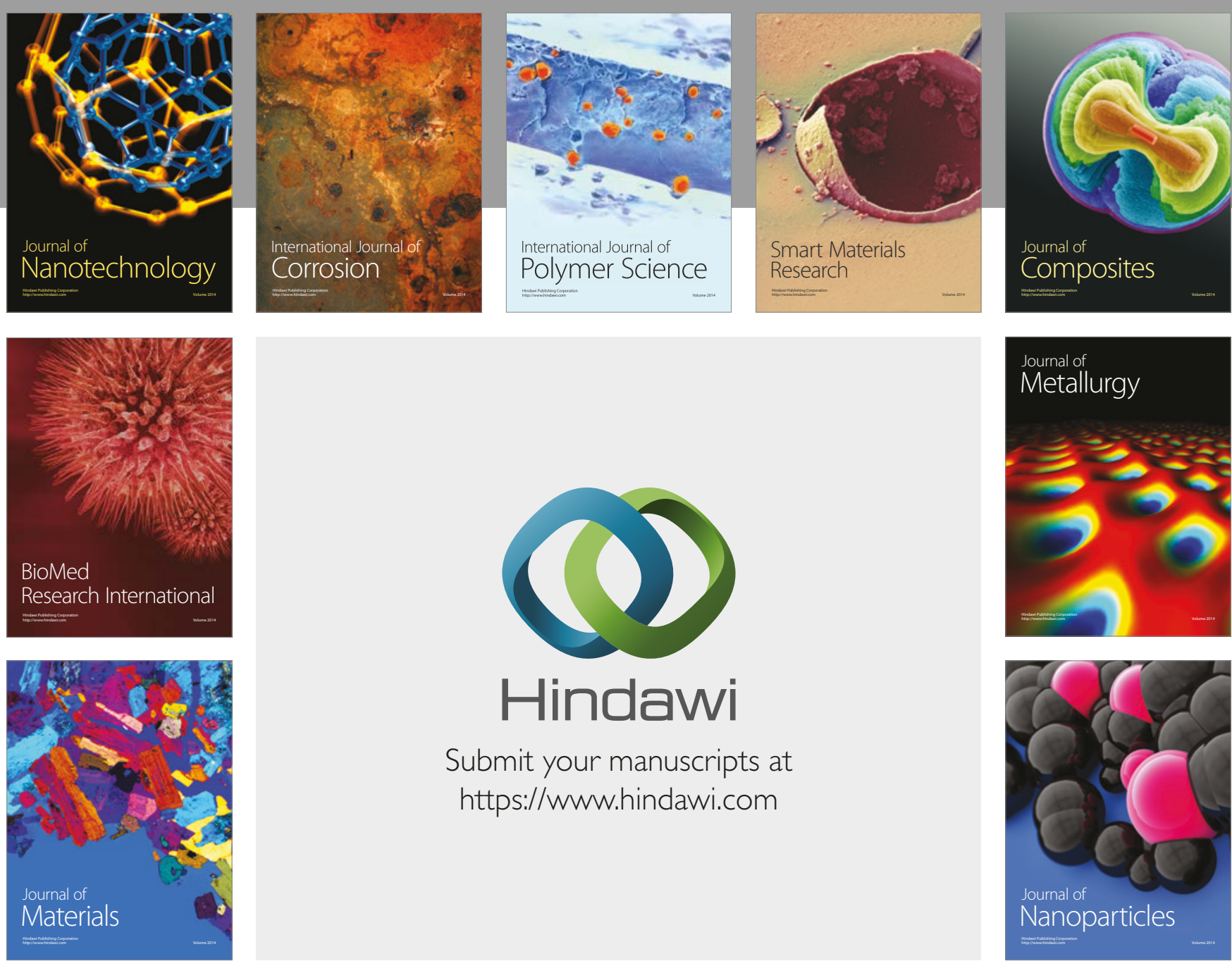

\section{Hindawi}

Submit your manuscripts at

https://www.hindawi.com
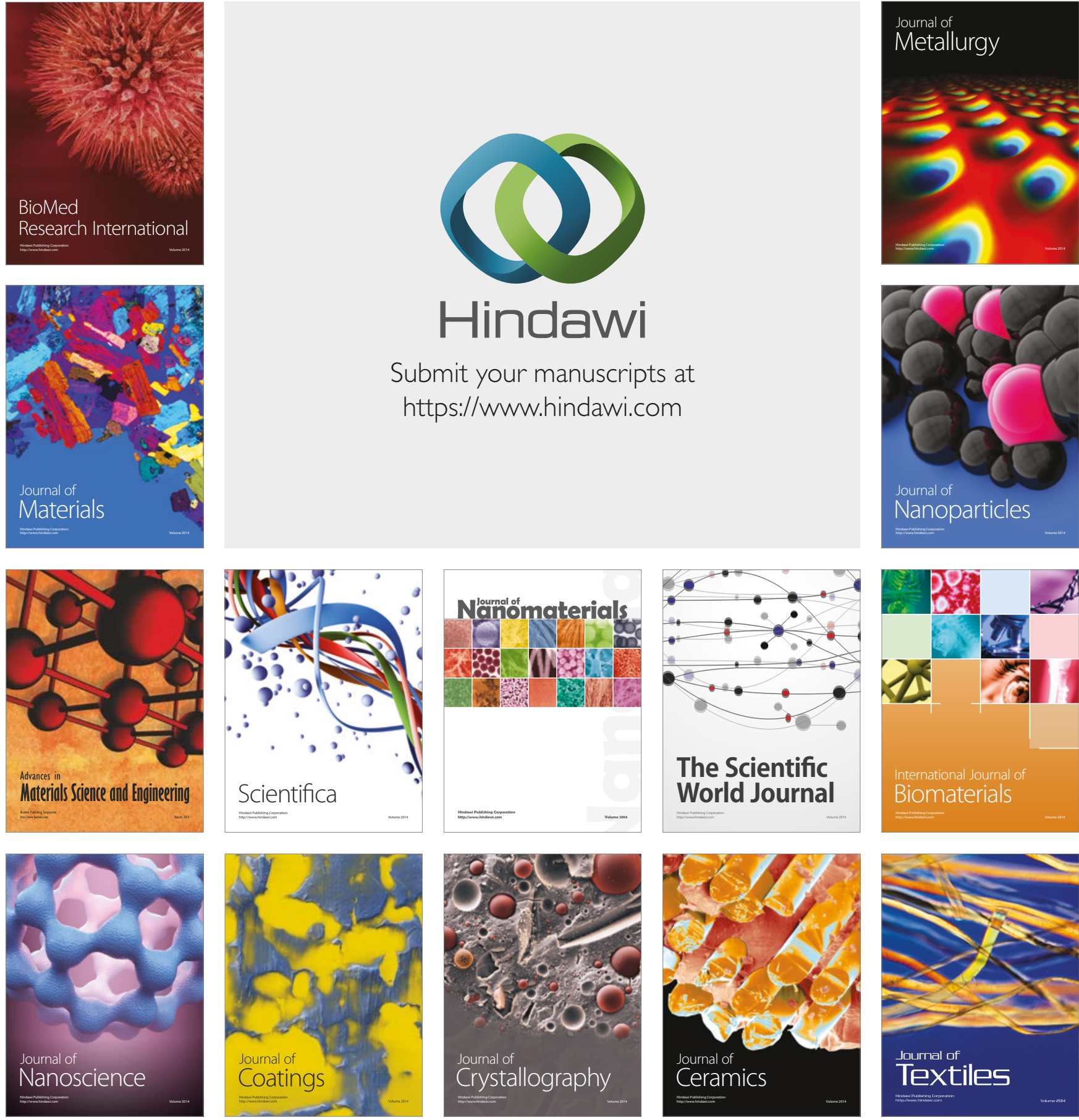

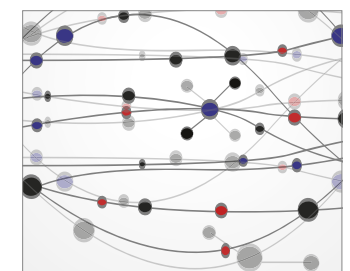

The Scientific World Journal
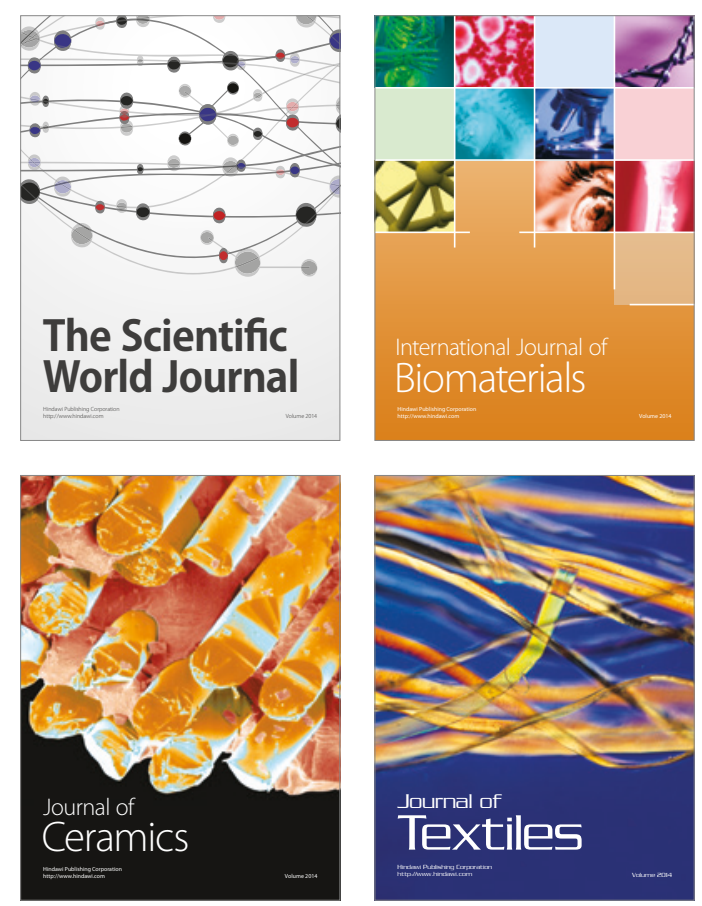